\title{
Pandemic A/H1N1v influenza 2009 in hospitalized children: a multicenter Belgian survey
}

\author{
Sophie Blumental ${ }^{1 * \dagger}$, Elisabeth Huisman ${ }^{2 \dagger}$, Marie-Coralie Cornet ${ }^{3}$, Christine Ferreiro ${ }^{4}$, Iris De Schutter ${ }^{2}$, \\ Marijke Reynders ${ }^{5}$, Ingrid Wybo ${ }^{6}$, Benoît Kabamba-Mukadi ${ }^{7}$, Ruth Armano ${ }^{3}$, Dominique Hermans ${ }^{3}$, \\ Marie-Cécile Nassogne ${ }^{3}$, Bhavna Mahadeb ${ }^{8}$, Christine Fonteyne ${ }^{9}$, Gerlant Van Berlaer ${ }^{10}$, Jack Levy ${ }^{4}$, Didier Moulin ${ }^{3}$, \\ Anne Vergison ${ }^{1,11}$, Anne Malfroot ${ }^{2}$ and Philippe Lepage
}

\begin{abstract}
Background: During the 2009 influenza A/H1N1v pandemic, children were identified as a specific "at risk" group. We conducted a multicentric study to describe pattern of influenza A/H1N1v infection among hospitalized children in Brussels, Belgium.

Methods: From July 1, 2009, to January 31, 2010, we collected epidemiological and clinical data of all proven (positive H1N1v PCR) and probable (positive influenza A antigen or culture) pediatric cases of influenza A/H1N1v infections, hospitalized in four tertiary centers.

Results: During the epidemic period, an excess of $18 \%$ of pediatric outpatients and emergency department visits was registered. 215 children were hospitalized with proven/probable influenza A/H1N1v infection. Median age was 31 months. $47 \%$ had $\geq 1$ comorbid conditions. Febrile respiratory illness was the most common presentation. 36\% presented with initial gastrointestinal symptoms and $10 \%$ with neurological manifestations. $34 \%$ had pneumonia. Only $24 \%$ of the patients received oseltamivir but $57 \%$ received antibiotics. $10 \%$ of children were admitted to PICU, seven of whom with ARDS. Case fatality-rate was 5/215 (2\%), concerning only children suffering from chronic neurological disorders. Children over 2 years of age showed a higher propensity to be admitted to PICU (16\% vs $1 \%, p=0.002$ ) and a higher mortality rate ( $4 \%$ vs $0 \%, p=0.06$ ). Infants less than 3 months old showed a milder course of infection, with few respiratory and neurological complications.

Conclusion: Although influenza A/H1N1v infections were generally self-limited, pediatric burden of disease was significant. Compared to other countries experiencing different health care systems, our Belgian cohort was younger and received less frequently antiviral therapy; disease course and mortality were however similar.
\end{abstract}

\section{Background}

On March 2009, in Mexico, a novel recombinant influenza strain $(\mathrm{A} / \mathrm{H} 1 \mathrm{~N} 1 \mathrm{v})$ of swine origin was discovered as an infective agent in humans [1]. This new virus spread rapidly, first to USA and Canada, then all over the world, causing the "new 2009 influenza A/H1N1v pandemic" [2]. Worldwide, the burden of disease was significant and subsequent efforts from health care systems were required to face an overload of patient's consultations as well as to implement vaccination and

\footnotetext{
* Correspondence: sophie.blumental@ulb.ac.be

+ Contributed equally

${ }^{1}$ Pediatric Infectious Diseases Unit, Hôpital Universitaire des Enfants Reine

Fabiola (HUDERF), Brussels, Belgium

Full list of author information is available at the end of the article
}

surveillance programs. Although consequences of the pandemic were less dramatic than initially feared, the World Health Organization (WHO) estimated that the virus was responsible of at least 17700 deaths worldwide and the Centers for Disease Control and Prevention (CDC) reported 59 millions infected people in the USA [3-5]).

During this A/H1N1v flu wave, children and young adults were identified as a particular risk group. They presented a higher attack rate than older adults [6] and a greater mortality rate than previously observed with classical seasonal flu $[7,8]$. Several reports on influenza $\mathrm{A} / \mathrm{H} 1 \mathrm{~N} 1 \mathrm{v}$ in pediatric settings have now been published [9-12], but information on clinical

\section{Ciomed Central}


presentation and severity of infection in European children remains limited [13-15]. However, these data could be of the great interest to guide future recommendations for vaccination and antiviral therapy during forecoming flu seasons.

Belgium experienced the influenza A/H1N1v epidemic from July 2009 to January 2010. Pandemic vaccine (adjuvanted Pandemrix ${ }^{\circledR}$ ) was only available after the peak occurred in October and was given with priority to risk groups (defined as health care workers, pregnant women and chronically ill patients) [16]. According to our national surveillance system, around 214531 people were infected, 733000 could benefit from vaccination and 19 deaths were attributable to the virus [17].

In this context, we conducted a multicenter study analyzing influenza $\mathrm{A} / \mathrm{H} 1 \mathrm{~N} 1 \mathrm{v}$ pediatric cases hospitalized in four tertiary medical centers of Brussels, Belgium. Our study aimed to offer a comprehensive description of influenza $\mathrm{A} / \mathrm{H} 1 \mathrm{~N} 1 \mathrm{v}$ infection in children, in the light of other recently published data from countries experiencing different health care systems [9-12].

\section{Methods}

\section{Study design and population}

In collaboration with infection control units and microbiology laboratories, we prospectively registered all proven and probable pediatric cases of influenza $A / H 1 N 1 v$ infections hospitalized in four tertiary facilities of Brussels (Hôpital Universitaire des Enfants Reine Fabiola, Universitair Ziekenhuis of Brussels, Cliniques Universitaires Saint-Luc and Hôpital Saint-Pierre). These facilities totalize 406 pediatric beds, representing $80 \%$ of the total pediatric beds available in Brussels (about 1 million inhabitants in 2009). Moreover, three of the hospitals have a Pediatric Intensive Care Unit (PICU) where critically-ill children from other hospitals of Brussels and the surrounding areas are referred to (in total 32 PICU beds available).

The study period extended from July 1, 2009, to January 31,2010 . Children were included if they were aged from 0 to 18 years, presented with clinical symptoms compatible with influenza (fever and/or respiratory signs/symptoms) and had either positive PCR results for influenza $\mathrm{A} / \mathrm{H} 1 \mathrm{~N} 1 \mathrm{v}$ (proven cases), or an antigen and/or a positive culture for influenza $A$ (probable cases). The latter cases were included because virtually no other seasonal influenza A viruses were circulating in Belgium during the epidemic period (less than $0.4 \%$, data from the Belgian National Institute of Public Health). Moreover, specific H1N1v PCR confirmation was no longer carried out routinely at the end of the epidemic, due to the high cost of this testing and the limited number of cases after December 2009.

\section{Data collection and definitions}

Data were collected retrospectively from patients' medical files using a standardized questionnaire.

A pre-existing co-morbidity was defined as a chronic condition requiring long term medication or medical follow up. Co-morbidities were listed based upon CDC H1N1 flu guidelines http://www.CDC.gov/h1n1flu.htm and other recent publications [8]. Co-morbidities were not mutually exclusive, so that a child could participate in several categories.

Fever was defined as a central temperature above $38^{\circ}$ Celsius.

Nosocomial infection was defined as a proven or probable case occurring after more than 48 hours of hospitalization.

\section{Microbiological testing}

Respiratory samples collection included nasopharyngeal aspirates, nasopharyngeal flocked swabs (Copan Diagnostics, Corona, CA), throat flocked swabs (Copan Diagnostics, Corona, CA) and sputum.

Antigen testing was assessed by immunochromatographic rapid antigen detection (RAT) in three of the four centers or also by direct immunofluorescence (DIF) technique (Argene SA, Verniolle, France) in one of them. Both DIF and immunochromatography use highly sensitive monoclonal antibodies directed against either influenza A or B nucleoprotein antigens [18]. RAT was performed using two different testing: the Coris Influ-A\&B Respi-Strip (Coris Bioconcept, Gembloux, Belgium) and the Binax Now influenza A \& B (Binax Inc., Inverness medical, Maine, USA). Direct antigen testing was unavailable in the fourth participating hospital, representing $26 \%$ of our cohort of patients.

Viral culture was performed on the three following cell lines: Vero, MRC-5 and LLC-MK2 in two centers; and MDCK, Hep-2, MRC-5 and LLC-MK2 in a third hospital, as described elsewhere [19]. In the fourth center which used DIF and RAT for antigen detection, respiratory samples were not cultured as antigen detection was followed directly by real-time PCR. (This center represented $22 \%$ of the cohort).

Biomolecular testing consisted, for three of the four centers, firstly in detection of influenza A virus by a home-made real-time RT-PCR (RT-PCR InflA) targeting the matrixprotein-coding gene and consequently by specific detection of the circulating pandemic variant using two monoplex real-time RT-PCR assays as described in the Centers of Disease Control (CDC) protocol: the SW InfA PCR (SWINE) and the SW H1 PCR (RT-PCR A/ H1N1) [20]. In the fourth center (26\% of samples), a commercial available PCR kit was used directly for detecting the pandemic strain: "Swine influenza virus 
(sw H1N1) Real-time PCR" (Diagenode Diagnostics, Liège, Belgium).

\section{Statistical analysis}

Statistical analyses were performed using Graph Pad Prism Software, Inc, 2003, San Diego, USA. Chi square or Fisher's exact tests were used to compare non continuous variables and Mann Whitney $\mathrm{u}$ - test was used to compare continuous variables. A two-tailed p-value less than 0.05 was considered as statistically significant.

\section{Ethical Consideration}

Approval of the Medical Ethics Committees of the four hospitals was obtained before starting the study. A code number was attributed to each child so that data collected remained strictly confidential.

\section{Results}

\section{Epidemiological Data}

During the epidemic period, an excess of 18\% (+10486) of pediatric outpatients and emergency department visits was registered, as compared with the mean measured over the 3 previous years during the same months. Figure 1 represents the evolution of H1N1v 2009 pediatric hospitalized cases over time in the four hospitals, with peak of the epidemic observed between the end of October and the beginning of November 2009. 215 children were hospitalized with proven or probable influenza A/ H1N1v infection; representing $2 \%$ of the total hospitals' admissions registered during the whole study period but $6 \%(191 / 3144)$ of those during the four weeks of the peak of the epidemic. Additionally, the PICU occupation rate by influenza $\mathrm{A} / \mathrm{H} 1 \mathrm{~N} 1 \mathrm{v}$ infected children was $3.5 \%$ over the whole study period and reached $8 \%$ during the peak of the epidemic.

Among our cohort of 215 children, 57\% were male. The median age of the patients was 31 months (range: < 1 to 208 months), with $19 \%$ of the children having less

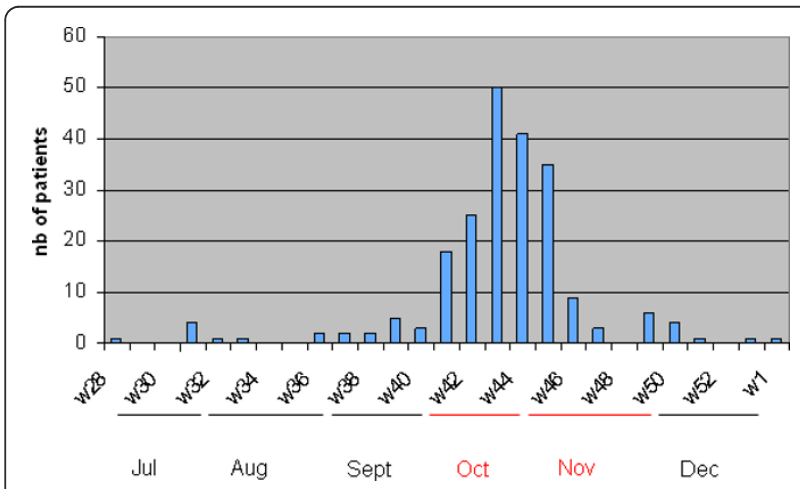

Figure 1 Epidemic curve of children hospitalized with influenza A/H1N1v infection. Brussels, July 2009-January 2010.

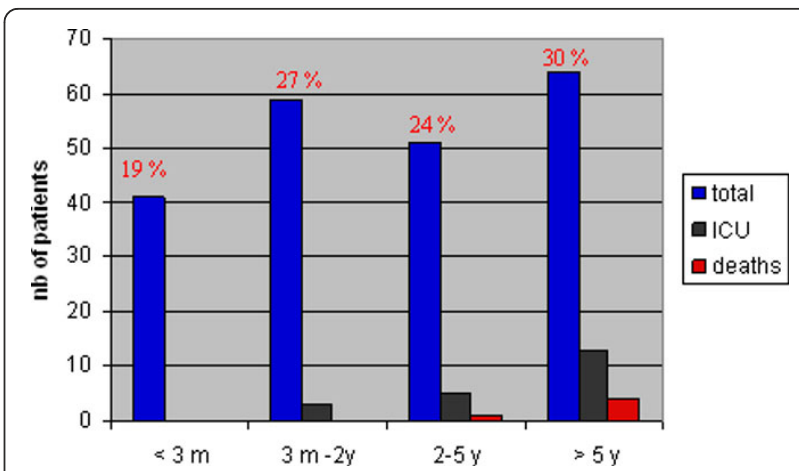

Figure 2 Age distribution of the $\mathbf{2 1 5}$ hospitalized children with influenza A/H1N1v infection. Brussels, July 2009-January 2010.

than 3 months of age (Figure 2). As shown in Table 1, $101 / 215$ (47\%) children presented with one or more underlying co-morbid condition, principally chronic lung diseases and neurological disorders. The median age of patients presenting co-morbidities was significantly higher than of those without (50 versus 14 months, $\mathrm{p}<0.0001$ ).

\section{Clinical Presentation and Diagnosis}

The major clinical features, reasons for hospitalization and blood diagnostic results are summarized in Table 2. The median duration of symptoms before admission was 2 days (IQR: 1-4 d). Presentation on admission consisted mainly in febrile respiratory illness, with a high prevalence of gastrointestinal symptoms, independently of age groups (Table 3). Moreover, 21 children (10\%) presented initially with neurological manifestations. Based upon initial clinical presentation, diagnosis of influenza $\mathrm{A} / \mathrm{H} 1 \mathrm{~N} 1 \mathrm{v}$ infection was suggested by clinicians in $56 \%$ of children (Table 2). $74 / 215$ (34\%) children had chest X-ray confirmed pneumonia, associated in $6 \%$ with pleural effusion. Three patients had confirmed bacterial superinfection with Streptococcus pneumoniae (positive blood cultures). For five patients (2\%), the influenza infection was hospital acquired.

As shown in Table 3, children aged less than 3 months old had a significantly lower rate of pneumonia and tended to have less neurological manifestations than older ones. For this age group, the main reason for hospitalization was surveillance of acute fever without focus. Initial clinical presentation was globally similar between patients with and without chronic co-morbidities, except for hypoxemia (Table 3).

Blood inflammatory profile on admission was variable, with $13 \%$ of the children presenting with leukopenia and 6\% with thrombocytopenia (Table 2). Respiratory samples collected to diagnose influenza A/ $\mathrm{H} 1 \mathrm{~N} 1 \mathrm{v}$ infection were nasopharyngeal aspirates and nasopharyngeal swabs in $58 \%$ and $39 \%$ of the patients, 
Table 1 Chronic co-morbid conditions in children hospitalized with influenza A/H1N1v infection in Brussels

\begin{tabular}{|c|c|c|c|c|}
\hline & Global cohort & Ward patients & PICU patients & \\
\hline & $N=215$ & $N=194$ & $N=21$ & \\
\hline $\mathrm{N}$ of Patients with $\geq 1$ co-morbidity (\%) & $101(47)$ & $88(45)$ & $13(62)$ & $p=0.1$ \\
\hline Distribution of co-morbidities & n (\%) & n (\%) & n (\%) & \\
\hline Chronic lung disease & $32(15)$ & $30(15)$ & $2(10)$ & \\
\hline Asthma & $18(8)$ & $18(9)$ & & \\
\hline Neurological disease & $31(14)$ & $26(13)$ & $5(24)$ & \\
\hline History of prematurity & $21(10)$ & $21(11)$ & none & \\
\hline median GA* (weeks) & $33 \mathrm{~W}$ & & & \\
\hline Hemato-oncology & $19(9)$ & $17(9)$ & $2(10)$ & \\
\hline $\mathrm{HSCT}^{* *}$ & $2(1)$ & $2(1)$ & & \\
\hline Sickle-cell disease & $8(4)$ & $7(4)$ & $1(5)$ & \\
\hline Congenital heart disease & $14(7)$ & $12(6)$ & $2(10)$ & \\
\hline surgically corrected & $6(3)$ & & & \\
\hline Malnutrition & $12(6)$ & $12(6)$ & none & \\
\hline Metabolic disease & $3(1)$ & $3(2)$ & none & \\
\hline Diabetes & $2(1)$ & $1(<1)$ & $1(5)$ & \\
\hline Renal disease & $3(1)$ & $2(1)$ & $1(5)$ & \\
\hline Solid organ transplant & $2(1)$ & $1(<1)$ & $1(5)$ & \\
\hline
\end{tabular}

Legend:* Gestational age, ${ }^{* *}$ Hematopoietic cell transplantation recipients

respectively. Compared to PCR (considered as the gold standard), the sensitivity of antigen by RAT was low, being only $29 \%(10 / 34)$ and $57 \%(47 / 83)$ using Coris RespiStrip and Binax Now testing, respectively (data not calculated for DIF method, as only performed on 11 samples). The sensitivity of culture was quite better at $76 \%(107 / 141)$.

\section{Treatments}

Among the 215 children, only 51 (24\%) received oseltamivir (doses according to weight and age [21]). For a large majority of them (37/47, data unavailable for three children), antiviral therapy was started directly on admission and was continued for five days (35/41, data unavailable for 9 patients). Rate of oseltamivir prescription reached $42 \%$ and $71 \%$ for children having pneumonia and for those requiring PICU admission, respectively. No significant related adverse events were reported. Oseltamivir was significantly more frequently prescribed among children older than 2 years compared to younger ones (Table 4) and among children with underlying disease (39/101 [39\%]) versus 12/114 [11\%], p < 0.0001). Additionally, 57\% (123/215) of the patients were treated with antibiotics, for a median duration of seven days. In only 17 of them (14\%), antibiotic therapy was discontinued after obtaining confirmation of influenza $\mathrm{A} / \mathrm{H} 1 \mathrm{~N} 1 \mathrm{v}$ infection (data unavailable for seven cases). Among children treated by antibiotics, 54\% had a diagnosis of pneumonia. Finally, antibiotics were similarly used in all patients' age groups (Table 4).

\section{Intensive Care}

$21 / 215$ patients $(10 \%)$ had to be admitted to PICU, mainly within 24 hours of admission. Among them, the prevalence of co-morbidity (62\%) tended to be higher than observed among ward patients, with a predominance of neurological disorders (Table 1). The median age of PICU children was 75 months (IQR 47-130). PICU admissions were significantly more frequent in children above two years of age (Table 4) and no infant less than three months old required intensive care.

The major reason for PICU admission was respiratory failure subsequent to pneumonia (Table 3). Seven patients (3\% of the global cohort) presented an Acute Respiratory Distress Syndrome (ARDS) and three had pleural effusion. Two patients were admitted for surveillance because of severe underlying disease. None of the 21 children presented seizures or signs of viral encephalitis (Table 3). The median duration of PICU stay was four days and ranged from 1 to 90 days. 13/21 (59\%) children received respiratory support with non invasive ventilation (NIV); eight (38\%) required mechanical invasive ventilation for a median duration of six days (range 1 to 45). One previously healthy child presenting with severe ARDS followed by cardiac-respiratory arrest had to undergo Extra Corporeal Membrane Oxygenation (ECMO) support during 12 days, but survived with mild respiratory sequelae.

\section{Clinical Outcome}

The median duration of hospitalization was three days (IQR: 2-6 d). This result was unaffected by the patients' age (Table 4). 
Table 2 Major clinical and laboratory findings in hospitalized children with influenza A/H1N1v infection

\begin{tabular}{|c|c|c|c|}
\hline \multirow[b]{2}{*}{ Presentation on admission } & \multirow{2}{*}{$\begin{array}{r}N=215 \\
n(\%)\end{array}$} & \multirow[b]{2}{*}{ Blood test values on admission } & \multirow[t]{2}{*}{$\mathrm{N}=201$} \\
\hline & & & \\
\hline \multirow[t]{2}{*}{ H1N1 suspicion } & $121(56)$ & Median Leukocyte count/mm3 & 9050 \\
\hline & & $\left(\mid Q^{*}\right)$ & $(6070-12060)$ \\
\hline Symptoms/signs & & $N(\%)$ of patients with leukopenia $\leq 5000 / \mathrm{mm}^{3}$ & $27(13)$ \\
\hline Fever & $188(88)$ & Median Lymphocyte count/mm3 & 2147 \\
\hline Cough & $129(60)$ & $(\mathrm{QQR})$ & $(1249-3632)$ \\
\hline Rhinorrhea & $105(49)$ & $N(\%)$ of patients with lymphopenia $\leq 1000 / \mathrm{mm}^{3}$ & $33(16)$ \\
\hline Loss of appetite & $58(27)$ & & \\
\hline Vomiting & $54(25)$ & Median PMN** count $/ \mathrm{mm}^{3}$ & 4378 \\
\hline Asthenia & $49(23)$ & $(\mathrm{IQR})$ & $(2667-8179)$ \\
\hline Diarrhea & $39(18)$ & $N(\%)$ of patients with neutropenia $\leq 1500 / \mathrm{mm}^{3}$ & $21(10)$ \\
\hline Convulsion & $21(10)$ & & \\
\hline Dehydration & $11(5)$ & Median Platelet count/mm3 & 297500 \\
\hline Headache & $11(5)$ & $(\mathrm{IQR})$ & $(211000-381500)$ \\
\hline Myalgia & $10(5)$ & $N(\%)$ of patients with thrombocytopenia $\leq 150.10^{3} / \mathrm{mm}^{3}$ & $12(6)$ \\
\hline Rash & $7(3)$ & & \\
\hline Abdominal pain & $5(2)$ & Median CRP*** (mg/dL) & 1.55 \\
\hline \multirow[t]{3}{*}{ Thoracic pain } & $5(2)$ & $(\mathrm{QQR})$ & $(<0.5-5.15)$ \\
\hline & & range & $<0.5-44.7$ \\
\hline & & $N(\%)$ of patients with $C R P>5 \mathrm{mg} / \mathrm{dl}$ & $51(25)$ \\
\hline Reason for hospitalization & n (\%) & $\underline{\text { Respiratory complications }}$ & n (\%) \\
\hline Altered general status & $89(41)$ & Hypoxemia $^{2}$ & $58(27)$ \\
\hline Respiratory distress & $78(36)$ & median oxygen saturation ${ }^{3}$ & $\begin{array}{r}90 \% \\
(85-92 \mathrm{lQR})\end{array}$ \\
\hline IV treatment & $67(31)$ & median duration of oxygen supplementation & 2.5 days \\
\hline Underlying disease & $53(25)$ & Lobar pneumonia & $57(27)$ \\
\hline $\mathrm{O} 2$ requirement & $52(24)$ & Diffuse pneumonia & $18(8)$ \\
\hline$<3$ months old & $41(19)$ & Pleural effusion & $13(6)$ \\
\hline Seizure/malaise & $22(10)$ & Apnea & $3(1)$ \\
\hline Anorexia/vomiting & $14(7)$ & Pneumothorax & $2(1)$ \\
\hline « Sepsis-like » illness & $6(3)$ & & \\
\hline Parental request/non compliance & $2(1)$ & & \\
\hline
\end{tabular}

Legend: * ${ }^{\mathrm{I}} \mathrm{QR}=$ interquartile range; ${ }^{* * \mathrm{PMN}}$ = polymorphonuclear leukocytes; ${ }^{* * *} \mathrm{CRP}$ = C-reactive protein; 1201 children with blood results available on admission; 2 defined as $\mathrm{Hb}$ oxygen saturation less than $94 \% ; 3$ transcutaneous saturation

Table 3 Clinical features of influenza A/H1N1v infection according to age, co-morbidity and PICU admission among hospitalized children

\begin{tabular}{|c|c|c|c|c|c|c|c|c|}
\hline & \multicolumn{8}{|c|}{ Clinical presentation } \\
\hline & Pneumonia & & Hypoxemia & & $\underline{\text { Seizures }}$ & & Gl* manifestations & \\
\hline & n (\%) & & n (\%) & & n (\%) & & n (\%) & \\
\hline Global cohort $(N=215)$ & $74(34)$ & & $58(27)$ & & $21(10)$ & & $78(36)$ & \\
\hline \multicolumn{9}{|l|}{ Age groups (months) } \\
\hline$<3$ months $(n=41)$ & $7(17)$ & $p=0.03$ & $4(10)$ & $p=0.01$ & $1(2)$ & $p=0.19$ & $13(32)$ & $p=0.74$ \\
\hline 3-24 months $(n=59)$ & $23(39)$ & & $15(25)$ & & $6(10)$ & & $21(36)$ & \\
\hline$>24$ months $(n=115)$ & $44(38)$ & & $39(34)$ & & $14(12)$ & & $44(38)$ & \\
\hline \multicolumn{9}{|l|}{ Co-morbidity } \\
\hline yes $(n=101)$ & $32(32)$ & $p=0.4$ & $34(34)$ & $p=0.03$ & $10(10)$ & $p=0.95$ & $33(33)$ & $p=0.3$ \\
\hline no $(n=114)$ & $42(37)$ & & $24(21)$ & & $11(10)$ & & $45(39)$ & \\
\hline \multicolumn{9}{|l|}{ PICU admission } \\
\hline yes $(n=21)$ & $15(71)$ & $\mathrm{p}<0.001$ & $18(86)$ & $p<0.001$ & $0(0)$ & $p=0.2$ & $5(24)$ & $p=0.2$ \\
\hline no $(n=194)$ & $59(30)$ & & $40(21)$ & & $21(11)$ & & $73(38)$ & \\
\hline
\end{tabular}

Legend:*Gl = gastrointestinal manifestations, including nausea, vomiting and/or diarrhea 
Table 4 Co-morbidity, treatment and outcome according to age in children hospitalized with influenza $A / H 1 N 1 v$ infection

\begin{tabular}{|c|c|c|c|}
\hline & \multicolumn{2}{|c|}{ Children's age groups } & \\
\hline & $<2$ years & $\geq 2$ years & \\
\hline & $\begin{array}{c}N=100 \\
(\%)\end{array}$ & $\begin{array}{c}N=115 \\
(\%)\end{array}$ & \\
\hline Rate of co-morbidity & $31(31)$ & $70(61)$ & $\begin{array}{c}p< \\
0.0001\end{array}$ \\
\hline \multicolumn{4}{|l|}{ Treatment } \\
\hline Oseltamivir & $11(11)$ & $40(35)$ & $p=0.001$ \\
\hline Antibiotics & $58(58)$ & $65(56)$ & \\
\hline PICU admissions & $3(3)$ & $18(16)$ & $p=0.002$ \\
\hline Invasive ventilation & $2(2)$ & $6(5)$ & \\
\hline $\begin{array}{l}\text { Median duration of } \\
\text { hospitalization (d) }\end{array}$ & 3 & 4 & $p=0.13$ \\
\hline Death & $0(0)$ & $5(4)$ & $p=0.06$ \\
\hline
\end{tabular}

The case-fatality rate among the global cohort was $2 \%$ (5/215). The five deaths were directly attributable to influenza $\mathrm{A} / \mathrm{H} 1 \mathrm{~N} 1 \mathrm{v}$ with or without bacterial superinfection and occurred in children with co-morbidities who would otherwise have died from their underlying disease. These underlying diseases consisted in neurological disorders from various etiologies (extensive central nervous system glioma, polymalformative syndrome, Hurler syndrome, cerebral palsy and severe encephalopathy with pontocerebellar hypoplasy). For all of them, severe pneumonia was notified, associated for three children with ARDS. All deaths concerned children aged more than two years old (Table 4). Four of the five children had received oseltamivir within 48 hours of clinical symptoms.

Three additional patients (1\%) were cured from influenza A/H1N1v infection but still suffered from sequelae at the end of the study (two had bronchiectasis with emphysema and one a pulmonary restrictive syndrome needing tracheotomy and NIV support at home).

\section{Discussion}

Even though consequences were less dramatic than initially feared, the 2009 influenza A/H1N1v pandemic has caused a significant burden of disease worldwide, especially in the pediatric population [6-8]. Higher attack rate was observed among children, causing important overload in outpatient and emergency departments [11] as well as in PICU [22]. Unfortunately, our study was not designed to assess the epidemiological impact of influenza $\mathrm{A} / \mathrm{H} 1 \mathrm{~N} 1 \mathrm{v}$ infection over the whole pediatric population of Brussels. Moreover, by selecting only laboratory confirmed infections, we underestimated the number of hospitalized cases, especially since diagnosis confirmation by PCR was no more routinely performed at the end of the epidemic. However, we were able to notice an important pediatric burden of disease in Brussels, as illustrated by an increased rate of outpatients visits of $18 \%$ during the epidemic period compared to the three previous years and a high rate of PICU occupation by influenza $\mathrm{A} / \mathrm{H} 1 \mathrm{~N} 1 \mathrm{v}$ infected patients ( $8 \%$ during the peak of epidemic). It would have been of interest to compare the rate of hospitalization related to H1N1 with those registered for seasonal flu during the 3 previous years but these data were unfortunately not available.

This study offers a comprehensive description of influenza A/H1N1v pattern of infection among Belgian hospitalized children, in the light of recent publications from other continents. Consistently with these reports [9-12,23,24], co-morbidities were highly prevalent among influenza $\mathrm{A} / \mathrm{H} 1 \mathrm{~N} 1 \mathrm{v}$ infected hospitalized children (47\%). The co-morbidities were not different from those observed during seasonal flu. As described by others $[7,9,22]$, the presence of at least one co-morbidity was significantly more frequent in children of more than two years of age and constituted a risk factor for severity of disease, in terms of PICU admissions and casefatality rate. Furthermore, influenza A/H1N1v illness course differed according to patients' age groups. Indeed, children less than two years of age (46\% of the cohort), and especially those less than three months, presented milder patterns of infection and were often hospitalized only for observation of fever without focus. $86 \%$ of PICU admissions and all deaths occurred in children over two years of age (with $80 \%$ of deaths among children $>$ five years old). Although this issue is conflicting in the medical literature $[7,10]$, similar findings have been reported in a large series by investigators from the CDC [25]. This observation differs from what is seen during seasonal flu, where young children and especially infants presented a higher mortality-rate compared to older ones [26,27]. Nevertheless, during this pandemic wave as well as during previous flu seasons, the highest rate of hospitalization was generally reported among young age groups $[8,9,11,24]$. This was particularly true in our series, as reflected by a median of age of 31 months, which was even younger than among American and Israeli hospitalized children (median age ranging from four to six years) $[9,10]$. If unexplained by the severity of infection, this finding probably illustrates differences in clinical practices and hospitalization policies. In Belgium, the National Healthcare System renders the access to inpatients pediatric facilities easy, so that hospitalization of infants presenting with fever without focus, especially those younger than 3 months of age, is largely recommended and not restricted to the most severe cases as in other countries [28,29].

Although we focused on hospitalized cases, influenza A/H1N1v episodes were mainly self-limited, consisting 
of febrile respiratory illness and requiring short duration of hospitalization (median 3 days) with or without oxygen supplementation. Initial clinical features did not differ from seasonal flu [30], except for the higher proportion of children presenting with gastrointestinal manifestations, as described in previous studies $[12,23,24]$. This involvement of the gastrointestinal tract could be subsequent to a high rate of influenza A/ H1N1v virus replication [31]. Neurological manifestations were also frequent ( $10 \%$ of children) but in contrast with other reports $[9,22]$ were not correlated with PICU admission or fatality. Finally, more than one third of the whole cohort and $71 \%$ of PICU patients had pneumonia confirmed on chest X-rays. Even though only $3(1 \%)$ children had evidence of bacteremia (all due to $S$. pneumoniae), it seems very likely that a significant proportion of pneumonia, especially those with lobar infiltrates, were associated with bacterial super-infections. According to some series, bacterial super-infections after influenza $\mathrm{A} / \mathrm{H} 1 \mathrm{~N} 1 \mathrm{v}$ episodes were found in about $4 \%$ of hospitalized children $[11,12,23]$ but reached 20 to $38 \%$ among fatal cases $[7,25,32]$. Considering the low rate of positive blood cultures $(\mathrm{BC})$ in pediatric bacterial community-acquired pneumonia (2.5 to $5 \%$ ) $[33,34]$, these published rates as well as our data likely constitute an under-estimation, as bacterial pneumonia diagnosis relied on positive cultures from sterile sites or autopsies and as part of children had received antibiotics prior to microbiological documentation. Finally, among our whole cohort, no necrotizing pneumonia, empyema or sepsis due to $S$. aureus or group A Streptococcus were reported, even though those pathogens are frequently involved in other series $[9,25]$.

Surprisingly, a majority of children were treated by antibiotics, even after the diagnosis of influenza A/ H1N1v infection was obtained. As mentioned above, confirming bacterial pulmonary super-infection after influenza illness is challenging and diagnostic relies more on clinical presumption and unspecific blood results [35]. However, this could only partly explain the high rate of antibiotics use, as only $54 \%$ of those children treated by antibiotics presented pulmonary infiltrates. Rate of antibiotics prescriptions was uniform among all age groups and was also high in other pediatric studies [10-12]. The exact reasons sustaining this practice remain unknown but should be worth to investigate in further prospective studies. Contrastingly, our study showed a particularly low percentage of oseltamivir prescriptions. Indeed, only $24 \%$ of the children were treated compared with 45 to $84 \%$ in other similar studies $[8,9,11,12]$. In our four centers, the use of oseltamivir was significantly higher in children above 2 years of age and/or suffering from comorbidities. This more "watch and wait" practice was in line with the restrictive national recommendations issued for oseltamivir pediatric use during the 2009 pandemic wave, which suggested cautious prescription under one year of age, regarding the absence of safety data among infants [16]. Moreover, in Belgium, prescription of antiviral drugs during seasonal flu is very limited and kept for management of severe diseases or immuno-compromised patients [36]. Obviously, the limitations associated with the retrospective design do not allow us to conclude on treatment efficacy. It is however interesting to note that, although oseltamivir was scarcely used, fatality rate and PICU admissions were comparable to the other above-mentioned reports $[9,10,12]$.

In Argentina [8], the case-fatality rate of influenza A/ H1N1v infected children was $5 \%$, with a global pediatric mortality rate 10 times greater compared to previous flu seasons. National surveys in the United Kingdom [7] and U.S [23] reported also a higher influenza related mortality rate during the pandemic influenza $\mathrm{A} / \mathrm{H} 1 \mathrm{~N} 1 \mathrm{v}$ than observed with seasonal flu. However, consequences in the Northern hemisphere were less dramatic than anticipated. Studies from these countries reported case-fatality rate among hospitalized children ranging from 0.6 to $3 \%$ [9-12], similar to our findings (2\%). As previously hypothesized [10], these North/South differences in patients' outcome could partly be explained by an easier access to the health care system in Europe, Israel and North America. In Israel [10], as well as in our series, the median duration of symptoms before hospitalization was only 2 days compared to 4 days in Argentina [8]. On another hand, 2 patterns of influenza A/H1N1v related deaths have been described [7]: those occurring after several days of hospitalization in chronically ill patients (80\%), in contrast to those observed after acute evolution of viral infection in previously healthy children (20\%). Despite a small number of cases, a similar profile seemed to happen in our series, as the five children who died suffered from chronic neurological disorders and one previously healthy child presented a fulminant viral infection causing cardio-respiratory arrest and requiring nine days of ECMO support to be cured.

\section{Conclusion}

Although influenza A/H1N1v infections were globally self-limited, pediatric burden of disease was significant. Children of more than 2 years old and/or suffering from chronic co-morbidities were shown at higher risk of severe infection. Compared to other countries experiencing different health care systems, our Belgian cohort was younger and received less frequently antiviral therapy; disease course and mortality were however similar.

\section{Acknowledgements}

We thank our colleagues Doyen M., RN, Biarent D., MD, Schurmans T., MD, for their careful management of patients during the H1N1 2009 epidemic and for their contribution in the realization of this study. 


\section{Author details}

${ }^{1}$ Pediatric Infectious Diseases Unit, Hôpital Universitaire des Enfants Reine Fabiola (HUDERF), Brussels, Belgium. ${ }^{2}$ Pediatric Pneumology and Infectious Diseases Department, Universitair Ziekenhuis Brussel (UZB), Brussels, Belgium. ${ }^{3}$ Department of Pediatrics, Cliniques Universitaires St-Luc (UCLouvain), Brussels, Belgium. ${ }^{4}$ Department of Pediatrics, Hôpital Universitaire St-Pierre, Brussels, Belgium. ${ }^{5}$ Microbiology Unit, Hôpital Universitaire St-Pierre, Brussels, Belgium. ${ }^{6}$ Microbiology Unit, UZB, Brussels, Belgium. ${ }^{7}$ Microbiology Unit, UCLouvain, Brussels, Belgium. ${ }^{8}$ Department of Pediatrics, HUDERF, Brussels, Belgium. ${ }^{9}$ Intensive Care Unit, HUDERF, Brussels, Belgium. ${ }^{10}$ Emergency and Intensive Care Unit, UZB, Brussels, Belgium. ${ }^{11}$ Infection Control Unit, HUDERF, Brussels, Belgium.

\section{Authors' contributions}

$S B, E H, I D S, J L, D M, A V, A M$ and $P L$ designed the study. SB, EH, MCC, CF, IDS, RA, DH, MCN, BM, CF and GVB collected patients' data. MR, IW and BKM performed microbiological testing. SB and PL performed data analysis. SB, EH and PL drafted the report. MCC, CF, IDS, RA, DH, MCN, BM, CF, GVB, JL, $\mathrm{DM}, \mathrm{AV}$ and $\mathrm{AM}$ revised the report. All authors read and approved the final manuscript.

\section{Competing interests}

The authors declare that they have no competing interests.

Received: 29 July 2011 Accepted: 7 November 2011 Published: 7 November 2011

\section{References}

1. Echevarria-Zuno S, Mejia-Aranguré JM, Mar-Obeso AJ Grajales-Muñiz C, Robles-Pérez E, González-León M, Ortega-Alvarez MC, Gonzalez-Bonilla C, Rascón-Pacheco RA, Borja-Aburto VH: Infection and death from influenza A H1N1 virus in Mexico: a retrospective analysis. Lancet 2009, 374:2072-2079.

2. Chan M: World now at start of 2009 influenza pandemic. World Health Organization 2009 [http://www.who.int/mediacentre/news/statements/2009/ h1n1_pandemic_phase6_20090611/en/index.html].

3. Pandemic (H1N1): 2009. update 94. Geneva. World Health Organization 2010.

4. CDC estimates of $2009 \mathrm{H} 1 \mathrm{~N} 1$ influenza cases, hospitalizations and deaths, in the United States, April 2009-February 13, 2010. Atlanta: Centers for Disease Control and Prevention 2010.

5. Writing Committee of WHO Consultation on Clinical aspects of pandemic (H1N1) 2009 influenza: Clinical aspects of pandemic 2009 influenza A (H1N1) virus infection. N Engl J Med 2010, 362:1708-1719.

6. Miller E, Hoschler K, Hardelid P, Stanford E, Andrews N, Zambon M: Incidence of 2009 pandemic influenza A N1N1 in England: a crosssectional serological study. Lancet 2010, 375:1100-1108.

7. Sachedina N, Donaldson LJ: Paediatric mortality related to pandemic influenza A H1N1 infection in England: an observational populationbased study. Lancet 2010, 376:1846-1852.

8. Libster R, Bugna J, Coviello S, Hijano DR, Dunaiewsky M, Reynoso N, Cavalieri ML, Guglielmo MC, Areso MS, Gilligan T, et al: Pediatric hospitalizations associated with 2009 pandemic influenza A (H1N1) in Argentina. N Engl J Med 2010, 362:45-55.

9. Louie J, Gavali S, Acosta M, Samuel MC, Winter K, Jean C, Glaser CA Matyas BT, Schechter R, California Pandemic (H1N1) Working Group: Children hospitalized with 2009 novel influenza A (H1N1) in California. Arch Pediatr Adolesc Med 2010, 164:1023-1031.

10. Stein M, Tasher D, Glikman D, Shachor-Meyouhas Y, Barkai G, Yochai AB, Leibovitz E, Hausman-Kedem M, Hess A, Megged O, Kassis I, Gresario G, Somekh E: Hospitalization of children with influenza A (H1N1) virus in Israel during the 2009 outbreak in Israel. Arch Pediatr Adolesc Med 2010, 164:1015-1022.

11. Miroballi Y, Baird S, Zackai S, Cannon JM, Messina M, Ravindranath T, Green R, Della-Latta P, Jenkins S, Greenwald BM, Furuya EY, Graham PL, Sonnett FM, Platt S, Delamora P, Saiman L: Novel influenza $A(H 1 N 1)$ in a pediatric health care facility in New York City during the first wave of the 2009 pandemic. Arch Pediatr Adolesc Med 2010, 164:24-30.

12. Bettinger JA, Sauvé LJ, Scheifele DW, Moore D, Vaudry W, Tran D, Halperin SA, Pelletier L: Pandemic influenza in Canadian children: a summary of hospitalized pediatric cases. Vaccine 2010, 28:3180-3184.
13. Hackett S, Hill L, Patel J, Ratnaraja N, Ifeyinwa A, Faroogi M, Nusgen U, Debenham P, Gandhi D, Makwana N, Smit E, Welch S: Clinical characteristics of paediatric H1N1 admissions in Birmingham, UK. Lancet 2009, 374:605.

14. Smit PM, Bongers KM, Kuiper RJ, von Rosenstiel IA, Smits PH, Brandjes DP: Characterization of 2009 H1N1 pandemic influenza in a population of Dutch children with influenza-like signs and symptoms. Acta Paediatr 2011.

15. Lera E, Worner NT, Sancosmed M, Fàbregas A, Casquero A, Melendo S, Miserachs M, Tórtola T, Borrego A, Campins M, Moraga F, Figueras C, Cebrián R: Clinical and epidemiological characteristics of patients with influenza A (H1N1) 2009 attended to at the emergency room of a children's hospital. Eur J Pediatr 2011, 170:371-78.

16. Commissariat interministériel Influenza/Interministerieel commissariat Influenza. Belgium. [http://www.influenza.be/fr/_documents/ 494403_GriepFlyer_FR.pdf].

17. Belgian National Influenza center. [http://www.iph.fgov.be/flu-surveillance/ ].

18. Reynders M, De Foor M, Maaroufi Y, Thomas I, Vergison A, Debulpaep S, Vandenberg O, Crokaert F: Prospective evaluation of Coris Influ-A\&B Respi-Strip and of Binax NOW Influenza A \& B assay against viral culture and Real-Time PCR Assay for Detection of 2009 Pandemic Influenza A/ H1N1v in Belgian patients. Acta Clin Belg 2011.

19. Leland D, Ginocchio CC: Role of Cell Culture for Virus Detection in the Age of Technology. Clin Microb Rev 2007, 20:49-78.

20. World Health Organization (WHO): CDC protocol of real time RTPCR for influenza A (H1N1) 2009.

21. Recommendations of the Advisory Committee on Immunization Practices (ACIP): Antiviral agents for the treatment and chemoprophylaxis of influenza. MMWR Recommendations and Reports 2011, 60:1-24.

22. Yung M, Slater A, Festa M, Williams G, Erickson S, Pettila V, Alexander J, Howe BD, Shekerdemian LS, Australia and New Zealand Intensive Care Influenza Investigators and the Paediatric Study Group and the Clinical Trials Group of the Australia New Zealand Intensive Care Society: Pandemic H1N1 in children requiring intensive care in Australia and New Zealand during winter 2009. Pediatrics 2011, 127:e156-163.

23. Skarbinski J, Jain S, Bramley A, Lee EJ, Huang J, Kirschke D, Stone A, Wedlake T, Richards SM, Page S, Ragan P, Bullion L, Neises D, Williams RM, Petruccelli BP, Vandermeer M, Lofy KH, Gindler J, Finelli L, 2009 Pandemic Influenza A H1N1 Virus Fall Hospitalizations Investigation Team: Hospitalized patients with 2009 pandemic influenza A (H1N1) virus infection in the United States-September-October 2009. Clin Infect Dis 2011, 52(S1):S50-59.

24. Centers for Disease Control and Prevention (CDC): 2009 pandemic influenza A (H1N1) virus infections, April- August 2009. MMWR Morb Mortal Wkly Rep 2009, 58:941-947.

25. Cox C, Blanton L, Dhara R, Brammer L, Finelli L: 2009 pandemic influenza A (H1N1) deaths among children-United States, 2009-2010. Clin Infect Dis 2011, 52(S1):S69-74.

26. Bhat N, Wright JG, Broder KR, Murray EL, Greenberg ME, Glover MJ, Likos AM, Posey DL, Klimov A, Lindstrom SE, Balish A, Medina MJ, Wallis TR, Guarner J, Paddock CD, Shieh WJ, Zaki SR, Sejvar JJ, Shay DK, Harper SA, Cox NJ, Fukuda K, Uyeki TM, Influenza Special Investigations Team: Influenza-associated deaths among children in the United States, 20032004. N Engl J Med 2005, 353:2559-2567.

27. Finelli L, Fiore A, Dhara R, Brammer L, Shay DK, Kamimoto L, Fry A, Hageman J, Gorwitz R, Bresee J, Uyeki T: Influenza-associated pediatric mortality in the United States: increase of Staphylococcus aureus coinfection. Pediatrics 2008, 122:805-811.

28. Ishimine P: Fever without source in children 0 to 36 months of age. Pediatr Clin N Am 2006, 53:167-194.

29. Baraff LJ: Management of infants and young children with fever without source. Pediatr Annals 2009, 37:673-679.

30. Glezen WP: Influenza viruses. In Textbook of Pediatric Infectious Diseases.. 6 edition. Edited by: Feigin RD, Cherry JD, Demmler-Harrisson GJ, Kaplan SL. Philadelphia: Saunders/Elsevier; 2009:2395-3413.

31. Munster VJ, de Wit E, van den Brand JM, Herfst S, Schrauwen EJ, Bestebroer TM, van de Vijver D, Boucher CA, Koopmans M, Rimmelzwaan GF, Kuiken T, Osterhaus AD, Fouchier RA: Pathogenesis and transmission of swine-origin 2009 A (H1N1) influenza virus in ferrets. Science 2009, 325:481-483. 
32. Mauad T, Hajjar LA, Callegari GD, da Silva LF, Schout D, Galas FR, Alves VA, Malheiros DM, Auler JO Jr, Ferreira AF, Borsato MR, Bezerra SM, Gutierrez PS, Caldini ET, Pasqualucci CA, Dolhnikoff M, Saldiva PH: Lung pathology in fatal novel human influenza A (H1N1) infection. Am J Respir Crit Care Med 2010, 181:72-79.

33. Shah SS, Alpern ER, Zwerling L, McGowan KL, Bell L: Risk of bacteremia in young children with pneumonia treated as outpatients. Arch Pediatr Adolesc Med 2003, 157:389-392.

34. Shah SS, Dugan MH, Bell LM, Grundmeier RW, Florin TA, Hines EM, Metlay JP: Blood cultures in the emergency department evaluation of childhood pneumonia. Pediatr Infect Dis I 2011, 30:475-79.

35. McIntosh K: Community-acquired pneumonia in children. $N$ Engl J Med 2002, 346:429-437.

36. Belgian Health Care Knowledge Center. [http://www.kce.fgov.be]

Pre-publication history

The pre-publication history for this paper can be accessed here: http://www.biomedcentral.com/1471-2334/11/313/prepub

doi:10.1186/1471-2334-11-313

Cite this article as: Blumental et al: Pandemic A/H1N1v influenza 2009 in hospitalized children: a multicenter Belgian survey. BMC Infectious Diseases 2011 11:313.

\section{Submit your next manuscript to BioMed Central} and take full advantage of:

- Convenient online submission

- Thorough peer review

- No space constraints or color figure charges

- Immediate publication on acceptance

- Inclusion in PubMed, CAS, Scopus and Google Scholar

- Research which is freely available for redistribution

Submit your manuscript at www.biomedcentral.com/submit 